\title{
Determination of Fatty Acid and Mineral Levels of Heat-Processed Sausages Produced in Turkey
}

\author{
Ahmet ÖZKAYA \\ Department of Chemistry, Faculty of Science and Letters, Adryaman University, 02040, Adryaman, Turkey \\ ORCID ID: Ahmet ÖZKAYA: https:// orcid.org/0000-0002-0173-3084
}

\begin{abstract}
Received: 21.02 .2020
Accepted: 25.02 .2020

Published online: 26.02 .2020

Issue published: 29.06 .2020

Abstract: Sausage is a meat product that is consumed in large quantities in Turkey. In the study, some mineral and fatty acid levels were determined in commercially produced sausages. For this purpose, 16 different brands of heat-processed sausages were obtained from national markets. Mineral and fatty acid levels were measured using Induced Coupled Plasma Mass Spectrophotometry (ICP-MS) and Gas Chromatography (GC) devices, respectively. Lead (Pb) 0.07, nickel (Ni) 0.31, iron (Fe) 39.83, zinc $(\mathrm{Zn})$ 15.92, copper $(\mathrm{Cu}) 1.26$, manganese $(\mathrm{Mn}) 2.61$, calcium $(\mathrm{Ca}) 425$, chrome $(\mathrm{Cr})$ 0.40, and aluminum $(\mathrm{Al}) 54.17$ ppm was determined in sausages. Among the major fatty acids in sausages, myristic acid (14:0) 3.080\%, palmitic acid (16:0) $26.216 \%$, palmitoleic acid (16:1) 3.414\%, stearic acid (18:0) 24.052\%, and oleic acid (18:1n9c) 36.952\% were determined. As a result, it is determined that the level of saturated fatty acids is high in the heat- processed sausages and the mineral levels are generally within the reference ranges.
\end{abstract}

Keywords: Sausage, nutritional level, fermented, toxic, fatty acid, mineral.

\section{Türkiye'de Üretilen Isıl İşlem Görmüş Sucukların Mineral ve Yağ Asit Düzeylerinin Tespiti}

Öz: Sucuk Türkiye' de önemli miktarda tüketilen bir et ürünüdür. Çalışmada, ticari olarak üretilen sucuklarda bazı mineral ve yă̆ asit düzeyleri tespit edilmiştir. Bu amaçla, 16 adet 1 sıl işlem görmüş farklı marka sucuk ulusal marketlerden temin edildi. Mineral ve yağ asitleri düzeyleri sırasıyla İndüklenmiş Eşleşmiş Plazma Kütle Spektrofotometresi (ICP-MS) ve Gaz Kromatografisi (GC) cihazları kullanılarak ölçüldü. Sucuklarda kurşun (Pb) 0.07, nikel (Ni) 0.31, demir (Fe) 39.83, çinko (Zn) 15.92, bakır (Cu) 1.26, mangan (Mn) 2.61, kalsiyum (Ca) 425, krom (Cr) 0.40 ve alüminyum (Al) 54.17 ppm olarak tespit edildi. Sucuklarda majör yağ asitlerinden miristik asit (14:0) \% 3.080, palmitik asit (16:0) \% 26.216, palmitoleik asit (16:1) \% 3.414, stearik asit (18:0) \% 24.052 ve oleik asit (18:1n9c) \% 36.952 olarak tespit edildi. Sonuç olarak; 1sıl işlem görmüş sucuklarda doymuş yağ asitleri düzeyinin yüksek olduğu ve mineral düzeylerinin ise genel olarak referans aralıklarında çıktığı tespit edilmiştir.

Anahtar kelimeler: Sucuk, besin düzeyi, fermente, toksik, yă̆ asidi, mineral.

\section{Giriş}

İnsanların sağlıklı olabilmesi için dengeli beslenmeleri önemlidir. Sağlıklı beslenme için et ve et ürünleri önemli bir yer tutmaktadır. Et ve et ürünlerinde yüksek düzeyde protein, mineral, vitaminler ve lipit bileşenleri vardır (Gökalp, Kaya, \& Zorba, 2002). Türkiye' de sucuk üretimi son yıllarda oldukça yaygınlaşmıştır. Geleneksel olarak üretilen Türk sucuğu fermantasyon işleminden sonra elde edilmektedir (Saviç, 1985). Sucuk yapımı için genel olarak sığır ve koyun etleri kullanılır. Sucuk, et ve et yağının kıyma haline getirildikten sonra, baharatlarla karıştırılarak doğal ya da yapay kılıflara doldurulmasıyla elde edilir. Hazırlanan sucuk belli bir sıcaklıkta olgunlaşır ve fermente sucuk elde edilir (Ertaş, 1985; Gökalp 1995). Ayrıca fermente sucuğun içeriğine starer kültürleri ilave edilerek sucuğun istenilen özelliklere gelmesi sağlanır (Lücke, 2000). Sucuğun tam olarak olgunlaşması için 9-12 güne ihtiyaç vardır. Ancak, sucuk üreticileri açısından bu süre uzun olduğundan dolayı ısıl işlemler uygulanarak bu süreç azaltılmaktadır. Fermantasyon işlemiyle elde edilen sucuk 1 sıl işlemlere $\left(45-70^{\circ} \mathrm{C}, 8-12\right.$ saat) maruz bırakılarak birkaç günlük süreçte hazır hale getirilir (Filiz, 2002; Gökalp, Kaya, \& Zorba, 2004; Ünal \& Karakaya, 2017). Isıl işleme maruz bırakılan sucukların PH değeri düşmektedir. $\mathrm{Bu}$ durum sucuğun tat ve renk gibi birçok özelliğini etkilemektedir (Gökalp et al., 2002; Lawrie, 1998). Isıl işleme maruz kalan sucuklarda oksidasyon hızı artar. Isıl işlemin sucuğun besinsel bileşenleri üzerine etkileri bulunmaktadır (Kanner, 1994; Gökalp et al., 2002).

Et ürünleri zengin mineral içeriklerine sahip olduğundan dolayı insan beslenmesinde önemli yer tutar. Ancak, insan kaynaklı çevresel kirlilikler su ve kara ekosistemi üzerine olumsuz etkiler oluşturmaktadır. Ağır metaller g1da zincirindeki toksisiteyi artırmaktadır (Eisler, 1988). İnsan sağlığını olumsuz etkileyen gıdalardaki ağır metal konsantrasyonları üzerinde son yıllarda birçok çalışma yapılmıştır (Farkas, Salanki, \& Specziar, 2003; Mansour \& Sidky, 2002; Tamate, 1987). Et ve et ürünlerindeki mineral seviyelerine birçok faktör etkili olmaktadır. Bu faktörlerden çevresel koşullar ve teknolojik işlemler en önemlileridir. Et Ürünlerindeki tüm mineraller besin yoluyla insanlara ve hayvanlara geçmektedirler (Demirezen \& Aksoy, 2004).

Fermentasyon aşamasında sucukların yapısında bulunan yağlarda değişimler olmaktadır. Yağların yapısını trigliseritler, fosfolipitler, digliseritler ve serbest yağ asitleri oluşturmaktadır. Fermentasyon süresince trigliserit, fosfolipit, digliserit düzeylerinde azalma olurken, serbest yağ asitlerinde artma olmaktadır. Bu durum fermentasyon süresince yağlarda lipoliz olayının 
gerçekleştiğini göstermektedir. Lipitlerin hidrolizi ve oksidasyonuna birçok faktör etki eder. Bu faktörler; etin işlenme süresi, sıcaklık ve $\mathrm{PH}^{\prime}$ dır (Visessanguana, Benjakulb, Riebroyb, Yarchaia, \& Tapingkae, 2006).

$\mathrm{Bu}$ çalışmada, Adıyaman şehrinde marketlerde satılan ısıl işlem görmüş fermente sucuklarda bazı yağ asit ve mineral düzeyleri araştırılmıştır.

\section{Materyal ve Yöntem}

\subsection{Isıl İşlem Görmüş Sucukların Temini}

Sucuk numuneleri, Türkiye'nin Adıyaman ilindeki marketlerden temin edilmiştir. 16 adet markadan satın alınan (ortalama 250 gr) sucuklar $4^{0} C^{\prime}$ de 1 gün muhafaza edildikten sonra deney aşamasında kullanılmıştır.

\subsection{Araçlar}

Et numunelerini yakma işlemi Berghof-MSW-4 marka mikrodalga cihazında yapıldı. Kadminyum (Cd), kurşun $(\mathrm{Pb})$, nikel $(\mathrm{Ni})$, demir $(\mathrm{Fe})$, çinko $(\mathrm{Zn})$, bakır $(\mathrm{Cu})$, mangan $(\mathrm{Mn})$, kalsiyum $(\mathrm{Ca})$, krom $(\mathrm{Cr})$ ve alüminyum $(\mathrm{Al})$ konsantrasyon düzeyleri ICP-MS Perkin Elmer-NexION 350X Markalı cihazla ölçüldü. Et numunelerinin yağ asit düzeyleri ise SHIMADZU GC 2025 gaz kromatografisi cihazı kullanılarak belirlendi.

\subsection{Kullanılan kimyasallar}

Kullanılan tüm kimyasallar analitik saflıktadır. Hekzan, sülfirik asit $\left(\mathrm{H}_{2} \mathrm{SO}_{4}\right)$, nitrik asit $\left(\mathrm{HNO}_{3}\right)$, izopropil alkol ve metanol Merck'ten satın alınd.

\subsection{Mineral analizi}

Sucuk numuneleri $(0.250 \mathrm{mg})$ alınarak üzerine $5 \mathrm{ml} \%$ 65'lik $\mathrm{HNO}_{3}$ eklendi ve mikrodalga cihazı kullanılarak çözdürüldü. Analizi yapılacak minerallerin $(\mathrm{Cd}, \mathrm{Pb}, \mathrm{Ni}$, $\mathrm{Fe}, \mathrm{Zn}, \mathrm{Cu}, \mathrm{Mn}, \mathrm{Ca}, \mathrm{Cr}$ ve $\mathrm{Al}$ ) uygun konsantrasyonlarda standart çözeltileri hazırlandı ve ICP-MS cihazında tüm minerallerin ölçümü yapıldı (Sahin et al., 2018). Analizler Adiyaman Üniversitesi Merkezi Araştırma Laboratuvarlarında yapılmıştır. Tablo 1'de mikrodalga ve Tablo 2' de ICP-MS cihazının çalışma şartları verilmiştir.

Tablo 1. Mikrodalga cihazı çalışma şartları

Table 1. Microwave device operating conditions

\begin{tabular}{lccc}
\hline Step & 1 & 2 & 3 \\
\hline $\mathrm{T}\left({ }^{\circ} \mathrm{C}\right)$ (Sıcaklık) & 160 & 190 & 50 \\
$\mathrm{P}$ (bar) (Basınç) & 40 & 40 & 0 \\
Güç (\%) & 80 & 80 & 0 \\
Çıış zamanı (Dakika) & 5 & 1 & 0 \\
Zaman (Dakika) & 5 & 15 & 0 \\
\hline
\end{tabular}

Tablo 2. ICP-MS cihazı çalışma şartları

Table 2. ICP-MS device operating conditions

\begin{tabular}{ll}
\hline Bileşen / Parametre & Tür / Değer / Mod \\
\hline Nebulizer & Mainhard(eşmerkezli) \\
Sprey Odası & Cam Siklonik \\
Üçlü Koni Arayüz Malzemesi & Nickel \\
Plazma Gaz Akışı & $18.0 \mathrm{~L} / \mathrm{min}$ \\
Yardımı Gaz Akışı & $1.2 \mathrm{~L} / \mathrm{min}$ \\
Nebulizatör Gaz Akışı & $0.90 \mathrm{~L} / \mathrm{min}$ \\
Örnek Alım Oranı & $1 \mathrm{~mL} / \mathrm{min}$ \\
RF gücü & $1500 \mathrm{~W}$ \\
Örnek başına kopya sayısı & 3 \\
Kullanma usulü, çalı̧̧̧a şekli & STD/KED Modu \\
& Çarpışma (He gazı kullanıldı) \\
\hline
\end{tabular}

\subsection{Yağ asidi analizi}

Sucuk numunelerinden (2 gr) alınarak hekzan/izopropil alkol (3:2) (h/h) karışımı içerisinde homojenize edildi (Hara \& Radin, 1978). Lipit ekstreleri 10000 rpm'de 10 dakika santrifüj edildi. Elde edilen lipit ekstrelerinde bulunan yağ asitleri \% 2'lik metanol/ $\mathrm{H}_{2} \mathrm{SO}_{4}(\mathrm{~h} / \mathrm{h}$ ) ile metil esterlerine dönüştürüldü (Christie, 1989). Oluşan yağ asitleri hekzan ile ekstre edilerek GC cihazında analizleri yapıldı. Her numune üç tekrarlı çalışılmıştır. GC cihazının okuma şartları önceki çalışmada belirtilmiştir (Özkaya, Sucak, Ağyar, \& Yilmaz, 2018).

\section{6. İstatistiksel analiz}

Yağ asitleri ve minerallerin tanımlayıcı istatistiksel değerleri SPPS 20.0 yazılım programında hesaplandı. Sonuçlar aritmetik ortalamatstandart error (SE) olarak verildi.

\section{Sonuçlar}

Tablo 3'te 1sıl işlem görmüş sucukların mineral düzeyleri belirtilmiştir. Isıl işlem görmüş sucuklarda mineral düzeyleri şu şekilde tespit edilmiştir; Ni 0.31, Fe 39.83, Zn 15.92, Cu 1.26, Mn 2.61, Ca 425, Cr 0.40, Al 54.17 ppm. Sucuklarin 11 adetinde ise $\mathrm{Pb} 0.07$ ppm olarak tespit edilmiştir. Bununla birlikte 5 adet sucuk örneğinde $\mathrm{Pb}$ bulunamamıştır. Ayrıca, ICP-MS cihazı okuma şartları altında kaldığı için Cd düzeyi de tespit edilememiştir.

Tablo 4'de 1sıl işlem görmüş sucukların \% yağ asit düzeyleri verilmiştir. Sucukların toplam doymuş yağ asit düzeyleri ( $($ SFA) \% 55.657, toplam tekli doymamış yağ asit düzeyi ( $(\mathrm{MUFA}) \% 41.425$, toplam çoklu doymamış yağ asit düzeyi ( $(P U F A) \% 2.918$ olarak tespit edildi. Majör yağ asitlerinden miristik asit (14:0) \% 3.080, palmitik asit (16:0) \% 26.216, stearik asit (18:0) \% 24.052, palmitoleik asit (16:1) \% 3.414, oleik asit (18:1n9c) \% 36.952 ve linolenik asit (18:2n6c) \% 2.918 olarak tespit edildi.

Tablo 3. Isıl işlem görmüş sucukların mineral düzeyleri (ppm)

Table 3. Mineral levels of heat-treated sausages (ppm)

\begin{tabular}{|c|c|c|c|c|c|}
\hline Mineraller(ppm) & Numune sayısı (16) & Minimum & Maksimum & Ortalama & SE \\
\hline $\mathrm{Cd}$ & 0 & - & - & - & - \\
\hline $\mathrm{Pb}$ & 11 & 0.04 & 0.13 & 0.07 & 0.01 \\
\hline $\mathrm{Ni}$ & 16 & 0.11 & 0.61 & 0.31 & 0.04 \\
\hline $\mathrm{Fe}$ & 16 & 23.68 & 84.27 & 39.83 & 3.63 \\
\hline $\mathrm{Zn}$ & 16 & 11.91 & 20.40 & 15.92 & 0.69 \\
\hline $\mathrm{Cu}$ & 16 & 0.88 & 1.88 & 1.26 & 0.08 \\
\hline Mn & 16 & 1.06 & 5.41 & 2.61 & 0.28 \\
\hline $\mathrm{Ca}$ & 16 & 243.00 & 573.00 & 425.00 & 21.00 \\
\hline $\mathrm{Cr}$ & 16 & 0.23 & 0.84 & 0.40 & 0.05 \\
\hline $\mathrm{Al}$ & 16 & 32.83 & 78.98 & 54.17 & 3.44 \\
\hline
\end{tabular}


Tablo 4. Isıl işlem görmüş sucukları yağ asit düzeyleri (\%)

Table 4 . Heat-treated sausages fatty acid levels (\%)

\begin{tabular}{|c|c|c|c|c|c|}
\hline Yağ asitleri & Numune sayısı (16) & Minimum & Maksimum & Ortalama & SE \\
\hline $10: 0$ & 16 & 0.046 & 0.082 & 0.061 & 0.002 \\
\hline $12: 0$ & 16 & 0.071 & 0.126 & 0.087 & 0.003 \\
\hline $13: 0$ & 16 & 0.018 & 0.052 & 0.030 & 0.002 \\
\hline $14: 0$ & 16 & 2.870 & 3.525 & 3.080 & 0.045 \\
\hline $15: 0$ & 16 & 0.383 & 0.505 & 0.464 & 0.009 \\
\hline $16: 0$ & 16 & 24.979 & 27.771 & 26.216 & 0.175 \\
\hline $17: 0$ & 16 & 1.016 & 1.287 & 1.160 & 0.019 \\
\hline $18: 0$ & 16 & 19.060 & 28.829 & 24.052 & 0.661 \\
\hline $20: 0$ & 16 & 0.155 & 0.228 & 0.189 & 0.004 \\
\hline $22: 0$ & 16 & 0.113 & 0.223 & 0.148 & 0.007 \\
\hline $24: 0$ & 16 & 0.033 & 0.499 & 0.170 & 0.029 \\
\hline$\sum$ SFA & & & & 55.657 & 1.850 \\
\hline $14: 1$ & 16 & 0.111 & 0.210 & 0.172 & 0.007 \\
\hline $16: 1$ & 16 & 1.795 & 4.147 & 3.414 & 0.136 \\
\hline $17: 1$ & 16 & 0.387 & 0.558 & 0.481 & 0.011 \\
\hline $18: \ln 9 \mathrm{c}$ & 16 & 33.627 & 40.859 & 36.952 & 0.565 \\
\hline $20: 1$ & 16 & 0.255 & 0.363 & 0.299 & 0.008 \\
\hline $22: 1 n 9$ & 16 & 0.084 & 0.182 & 0.107 & 0.006 \\
\hline$\sum$ MUFA & & & & 41.425 & 1.140 \\
\hline $18: 2 \mathrm{n} 6 \mathrm{c}$ & 16 & 2.362 & 3.296 & 2.918 & 0.094 \\
\hline$\sum$ PUFA & & & & 2.918 & 0.094 \\
\hline$\sum$ USFA & & & & 44.343 & 1.56 \\
\hline
\end{tabular}

\section{Tartışma}

Araştırmada Türkiye'de ticari amaçla üretilen isıl işlem görmüş sucukların bazı yağ asit ve mineral düzeyleri tespiti yapılmıştır.

Araştırma sonuçlarımıza göre, sucuk örneklerinde doymuş yağ asitleri düzeyi yüksek bulunmuştur (14:0 $\% 3.080, \quad 16: 0 \% 26.216$ ve 18:0 \%24.052). Ayrica çalışmamızda doymamış yağ asitlerinden 18:1n9c \%36.952 olarak bulundu. Türkiye'de yapılan bir çalışmada, sucukların yă̆ asit düzeyleri 14:0 \%2.99, 16:0 \%24.72, 18:0 \%15.92 ve 18:1 \%41.92 olarak rapor edilmiştir (Ünal \& Karakaya, 2017). Sucuklarla yapılan farklı bir çalışmada; $14: 0 \% 2.46,16: 0 \% 21.32,18: 0 \% 18.04$ ve $18: 1 n 9$ c $\% 46.24$ düzeyinde yağ asitleri tespit edilmiştir (Kayardı \& Gök, 2003). Gök sucuklarla yaptığı çalışmada, 14:0 \%2.81-2.86, $16: 0 \% 24.22-24.55,18: 0 \% 20.9-21.3$ ve $18: 1 n 9 c$ \% 42.63-43.20 düzeyinde majör yağ asitlerini tespit etmiştir (Gök, 2006). Ercoşkun yapmış olduğu bir çalışmada ise 1 sıl işlem öncesi ve sonrası fermente sucukların yağ asit düzeylerini incelemiştir. Isıl işlem öncesi ve 6 gün 1 sıl işlem maruz birakılan sucuklarda; 14:0 \%3.36-3.44, 16:1 \%2.85-2.92, 18:0 \%33.38-33.64, 18:1 \%24.53-245.45, 18:3 \%0.19-0.12 yă̆ asit düzeylerini tespit ettiğini rapor etmiştir (Erçoşkun, 2006). Çalışmamızda, sucuklarda tespit ettiğimiz majör yă̆ asitleri ile yukarıda belirtilen literatür sonuçları arasında farkların olduğunu düşünmekteyiz. Sucuklara uygulanan işlemlerden ve sucukların içeriğindeki katkılardan dolayı sucukların besinsel düzeylerinde farklılıklar olmaktadır (Visessanguan, Benjakul, Riebroy, Yarchai, \& Tapingkae, 2006).

Et ve et ürünleri mineraller yönünden oldukça zengindir. Ancak, insanların oluşturduğu çevresel kirlilikler sonucunda ağır metaller su ve toprağa karışmaktadır. Hayvanların ağır metallerle kirlenmiş topraklarda beslenmesi ve suyu içmesi sonucunda metabolizmasına bu metaller geçmektedir. Hayvansal besinleri tüketen insanlara da geçtiğinden dolayı ağır metaller ciddi hastalıklara neden olmaktadır. Yapılan çalışmalarda et ve et ürünlerindeki ağır metallerin düzeylerine dikkat çekilmiștir (Eisler, 1988; Mansour \&
Sidky, 2002; Moiseenko \& Kudryavtseva, 2001; Demirezen \& Aksoy, 2004).

Çalışmada, ağır metallerden $\mathrm{Pb}$ düzeyi 11 adet örnekte (0.07 ppm) tespiti yapılırken, 5 adet örnekte tespiti yapılamadı. Isıl işlem görmüş sucukların 16 adetin de ise Ni 0.31, Fe 39.83, Zn 15.92, Cu 1.26, Mn 2.61, Ca 425, Cr 0.40, Al 54.17 ppm olarak tespit edildi. Ayrıca tüm numunelerde $\mathrm{Cd}$ düzeyi tespit edilemedi. Yapılan literatür araştırmalarında, Türkiye' de ısıl işlem görmüş sucukların içeriğindeki ağır metal düzeyleri tespiti çalışmalarının çok az olduğu tespit edildi. Türkiye' nin bir ili olan Kayseri'de sucuk ve pastırma gibi et ürünleri üretimi oldukça yaygındır. Kayseri bölgesinden temin edilen sucukların mineral düzeyleri Cu 8.1, Fe 107.1, Cd 0.82, Cr 8.71, Mn 7.3, $\mathrm{Ni} 24, \mathrm{~Pb}$ 12.8, Se 3.9 ve $\mathrm{Zn} 49 \mu \mathrm{g} 100 \mathrm{~g}^{-1}$ olarak rapor edilmiştir (Demirezen \& Uruç, 2006). Çalışmamızın en önemli sonuçlardan biri sucuklarda $\mathrm{Pb}$ düzeyinin tespitidir. Ancak, çalışmamızda $\mathrm{Pb}$ düzeyinin belirtilen aralıkların altında olduğunu gözlemledik. Gıdalarda kabul edilen $\mathrm{Pb}$ düzeyi 0.4-0.5 ppm aralığ1dır (EC, 2001; FAO, 1983). Kurşun, çocuklarda bilişsel gelişim ve kan basıncını azaltmaktadır. Ayrıca, kardiyovasküler hastalıklara neden olduğu bilinmektedir (Commission of the European Communities, 2001).

$\mathrm{Cu}$ düzeyi çalışmada $1.26 \mathrm{ppm}$ olarak tespit edilmiştir. Çocuklar için (1-3 yaş) ve erkekler ve kadınlar (19-70 yaş) için tolere edilebilir $\mathrm{Cu}$ alım düzeyi sırasıyla 1 ve $10 \mathrm{mg} \mathrm{d}^{-1}$ dir. Fe miktarı ise çocuklarda ( 0 ay- 8 yaş) ve erkeklerde ve kadınlarda (14-70 yaş) üst tolere edilebilir Fe alımı sırasıyla 40 ve $45 \mathrm{mg} \mathrm{d}^{-1}$ dir. Çalışmamızda analizi yapilan sucuklarda $\mathrm{Cu}$ ve $\mathrm{Fe}$ düzeylerinin uygun konsantrasyonlar aralığında olduğu görülmektedir (Institute of Medicine, 2003). 51-70 yaş arası kadınlar ve erkekler için krom için üst tolere edilebilir alım seviyesi sırasiyla 20 ve $30 \mathrm{mg} \mathrm{d}^{-1}$ dir (Institute of Medicine, 2002). Çalışmamızda sucuklarda Ni düzeyinin oldukça az çıktığı görülmektedir. Sucuklarda Mn seviyesi 2.61 ppm olarak tespit edilmiştir. Uluslararası Tıp Örgütü (2003) Mn için, çocuklarda (1-3 yaş) ve erkekler / kadınlarda (19-70 yaş) için tolere edilebilir üst Mn düzeyini sırasıyla 2 ve $11 \mathrm{mg}$ $\mathrm{d}^{-1}$ olarak belirtmiştir (Institute of Medicine, 2003). Çalışmada sucuklarda tespit ettiğimiz Mn düzeyinin limit 
aralığında olduğu görülmektedir. Mn insanlarda büyüme ve sağlık için çok önemlidir. Mn alımının az olması halinde sinir sistemi sorunları ortaya çıkar. Çinko insan metabolizması için elzem bir elementtir. Birçok enzimin aktivasyonu için gereklidir. Zn'nin çocuklar (1-3 yaş), erkekler ve kadınlar (19-70 yaş) için üst tolere edilebilir çinko alımı sırasıyla 0.2 ve $1 \mathrm{mg} \mathrm{d}^{-1}$ dir (Institute of Medicine, 2003).Sucuklarda Zn düzeyi 15.92 ppm olarak tespit edilmiştir. Bu düzeyin yüksek olması toksisiteye neden olabileceği düşünülmektedir. Metobolizmada çinkonun azlığı sorunlara neden olabildiği gibi fazlalığı da insan sağlığına zararlı olabilmektedir (Agency for Toxic Substances \& Disease Registry, 2004; Institute of Medicine, 2003). Çalışmada Ca düzeyi $425 \mathrm{ppm}$ olarak tespit edilmiştir. Sı̈ır etinde tespit edilen Ca düzeyi 890-995 ppm aralığında rapor edilmiştir (Tasic et al., 2017). Çalışmada $\mathrm{Al}$ düzeyi 54.17 ppm olarak tespit edilmiştir. Yapılan literatürlerde sucuk içeriğindeki Al düzeylerine rastlanmamıştır.

Sonuç olarak, Türkiye'de ticari amaçla üretilen 1sıl işleme görmüş sucukların doymuş yağ asit düzeyinin yüksek olduğu ve minerallerin genel olarak referans aralıklarında olduğu düşünülmektedir.

Teşekkür: Bu çalışma Adıyaman Üniversitesi Bilimsel Araştırma Projeleri Birimi tarafından FEFYL/2015-0006 numaralı proje ile desteklenmiştir.

\section{Referanslar}

Agency for Toxic Substances and Disease Registry (2004). Agency for Toxic Substances and Disease Registry, Division of Toxicology, Clifton Road, NE, Atlanta, GA. Retrieved from http:// www.atsdr.cdc.gov/toxprofiles/

Commission of the European Communities (2001). Commission Regulation (EC) No. 221/2002 of 6 February 2002 amending regulation (EC) No. $466 / 2002$ setting maximum levels for certain contaminants in foodstuffs. Official Journal of the European Communities, Brussels, 6 February 2002.

Christie, W.W. (1989). Gas chromatography and lipids: a practical guide. Ayr, Scotland, The Oily Press., 307 pp.

Demirezen, D., \& Aksoy, A. (2004). Accumulation of heavy metals in Typha angustifolia (L.) and Potamogeton pectinatus (L.) living in Sultan Marsh (Kayseri, Turkey). Chemosphere, 56(7), 685-696. doi.org/10.1016/j.chemosphere.2004.04.011

Demirezen, D., \& Uruc, K. (2006). Comparative study of trace elements in certain fish, meat and meat products. Meat Science, 74(2), 255-260. doi: 10.1016/i.meatsci.2006.03.012.

EC, (2001). Commission Regulation No. 466/2001 of 8 March 2001. Official Journal of European Communities 1.77/1.

Eisler, R. (1988). Zink Hazards to fish, Wildlife and Invertebrates: a synoptic review. US Fish Wildlife Service Biology of Reproduction, 85.

Ercoşkun, H. (2006). Isıl İşlem Uygulanarak Üretilen Sucukların Bazı Kalite Özelliklerine Fermentasyon Süresinin Etkileri. Doktora Tezi, Ankara Üniversitesi, Fen Bilimleri Enstitüsü, Ankara.

Ertaş, A.H (1985). Et ürünlerinin üretim teknikleri ve mikroorganizmalar. Kükem Dergisi, 8(2), 131-133.

FAO, (1983). Compilation of Legal Limits for Hazardous Substance in Fish and Fishery Products (Food and Agricultural Organization). FAO Fishery circular, 464, 5-100.

Farkas, A., Salanki, J., \& Specziar, A. (2003). Age and size-specific patterns of heavy metals in the organs of freshwater fish Abramis brama L. populating a low-contaminated site. Water Research, 37(5), 959-964. doi.org/10.1016/S0043-1354(02)00447-5

Filiz, N. (2002). Yüksek Isı uygulaması ile üretilen "türk sucuklarında" starter kültür kullanımı. İstanbul Üniversitesi Veteriner Fakültesi Dergisi, 28(1), 17-29.

Gök, V. (2006). Antioksidan kullanımının fermente sucukların bazı kalite özellikleri üzerine etkileri. Doktora Tezi, Ankara Üniversitesi, Fen Bilimleri Enstitüsü, Ankara, Türkiye.

Gökalp, H.Y. (1995). Fermente et ürünleri-Sucuk üretim teknolojisi. Standart Ekonomik ve Teknik Deroi, Özel Sayısı 34, 48-55
Gökalp, H.Y., Kaya, M., \& Zorba, Ö. (2002). Et ürünleri işleme mühendisliği. Atatürk Üniversitesi Yayın No: 786. Erzurum, Türkiye, Atatürk Üniversitesi Ziraat Fakültesi Ofset Tesisi, 561 pp.

Gökalp, H.Y., Kaya, M., Zorba, Ö. (2004). Et ürünleri işleme mühendisliği. Erzurum, Türkiye, Atatürk Üniversitesi Ziraat Fakültesi Ofset Tesisi, 468 pp.

Hara, A., \& Radin, N.S. (1978). Lipid extraction of tissues with a low-toxicity solvent. Analytical Biochemistry, 90, 420-426.

Institute of Medicine. (2002). Dietary Reference intakes for vitamin A, vitamin $\mathrm{K}$, arsenic, boron, chromium, copper, iodine, iron, manganese, molybdenum, nickel, silicon, vanadium, and zinc. Washington, DC, USA, Institute of Medicine of the National Academies, The National Academy Press., 773 pp.

Institute of Medicine. (2003). Dietary Reference intakes: applications in dietary planning. subcommittee on interpretation and uses of dietary reference intakes and the standing committee on the scientific evaluation of dietary reference intakes. Washington, DC, USA, Institute of Medicine of the National Academies, The National Academies Press., 248 pp.

Kayaardı, S., \& Gök, V. (2003). Effect of replacing beef fat with olive oil on quality characteristics of Turkish soudjouk (sucuk). Meat Science, 66(1), 249-257. doi: 10.1016/S0309-1740(03)00098-6.

Kanner, J. (1994). Oxidative processes in meat and meat products. Meat Science, 36, 169-189

Lawrie, R. A. (1998). Lawrie's meat science. Abington, Cambridge, England, Woodhead Publishing Limited, $442 \mathrm{pp}$

Lücke, K.F (2000). Utilization of microbes to process and preserve meat. Meat Science, 56(2), 105-115. doi.org/10.1016/S0309-1740(00)00029-2

Mansour, S.A., \& Sidky, M.M. (2002). Ecotoxocological Studies. 3. Heavy metals contaminating water and fish from Fayoum Governorate, Egypt. Food Chemistry, 78, 15-22.doi: 10.1016/S0308-8146(01)00197-2

Moiseenko, T.I., \& Kudryavtseva, L.P. (2001). Trace metal accumulation and fish pathologies in areas affected by mining and metallurgical enterprises in the Kola Region. Russian Environmental Pollution, 114(2), 285-297. doi.org/10.1016/S0269-7491(00)00197-4

Özkaya, A., Sucak, M.G., Ağyar, O., \& Eray Yılmaz. (2018). Determination of Mineral and Fatty Acid Concentrations of Akkaraman Sheep's Milk. Commagene Journal of Biology, 2(2), 1-4. doi:10.31594/commagene.420718

Sahin, Z., Ozkaya, A., Uckun, M., Yologlu, E., Kuzu, ., Comakli, V., Demirdag, R., Tel, A.Z., Aymelek, F.F., \& Yologlu, S. (2019). Evaluation of the effects of Cyclotrichium niveum on brain acetylcholinesterase activity and oxidative stress in male rats orally exposed to lead acetate. Cellular and Molecular Biology, 65(5), 3-8. doi: 10.14715/cmb/2019.65.5.2

Savic, I.V, (1985). Small-scale sausage production, Fao Animal Production and Health Paper 52. FAO Publications Division, Via delle Terme di Caracalla, 00100 Rome, Italy.

Tamate, R. (1987). Distribution, content and variation of minerals in meat and meat products. Japanese Journal of Dairy and Food Science, 36, A1.

Tasic, A., Kureljusic, J., Nesic, K., Rokvic, N., Vicentijevic, M., Radovic, M., \& Pisinov B. (2017). Determination of calcium content in mechanically separated meat. 59th International Meat Industry Conference MEATCON2017. doi:10.1088/1755-1315/85/1/012056.

Ünal, K., \& Karakaya, M. (2017). The Effect of Clove and Cinnamon on Some Physicochemical Properties of Sucuk Produced by Different Animal Fat Types. Journal of Tekirdag Agricultural Faculty, 14 (03), 55-65.

Visessanguan, W., Benjakul, S., Riebroy, S., Yarchai, M., \& Tapingkae, W. (2006). Changes in lipid composition and fatty acid profile of Nham, aThai fermented pork sausage, during fermentation. Food Chemistry, 94(4), 580-588.doi: 10.1016/i.foodchem.2004.11.051 